\title{
Sulama Kanal Çeşitleri ve Uzunluklarının Sulama Performans Göstergelerine Etkisi
}

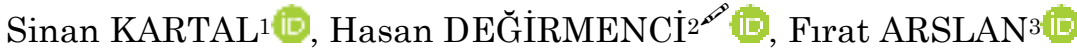 \\ ${ }^{1}$ Akdeniz Üniversitesi, Kumluca Meslek Yüksekokulu, Bitkisel ve Hayvansal Üretim Bölümü, 07350 Kumluca Antalya, ${ }^{2}$ Kahramanmaraş \\ Sütçü İmam Üniversitesi, Ziraat Fakültesi, Biyosistem Mühendisliği Bölümü, 46040, Kahramanmaraş, \\ ${ }^{1}$ https://orcid.org/0000-0002-9600-8052, ${ }^{2}$ https://orcid.org/0000-0002-6157-816X, ${ }^{3}$ https://orcid.org/0000-0002-7168-226X \\ $\bowtie$ : hdegirmenci46@gmail.com
}

\section{ÖZET}

Suyun etkin kullanımında sulama şebekelerinde kullanılan kanal çeşitleri büyük öneme sahiptir. Bu çalışmada, Ege Bölgesinde 9 adet sulama şebekesinde, ana sulama kanal çeşitleri ve uzunluklarının sulama performans göstergelerine etkisi araştırılmıştır. Sulama kanal uzunlukları ve su iletim performans göstergeleri arasındaki ilişkiyi araştırmak amacıyla korelasyon; kanal çeşitlerine ve uzunluklarına göre sulama şebekelerini homojen gruplara ayırmak amaciyla kümeleme analizi ve genel değerlendirme yapmak amaciyla da temel bileşenler analizi sonucunda oluşan biplot grafikleri kullanılmıştır. Sonuçta, kanal uzunlukları ve çeşitleri ile sulama oranı ve birim sulama alanına dağıtılan toplam sulama suyu miktarı arasında korelasyon bulunmuştur $(\mathrm{P}>0.01)$. Sulama kanal çeşitleri ve uzunlukları ile birim sulanan alana dağıtılan toplam sulama suyu miktarı ve su temin oranı arasındaki ilişki istatistiksel olarak anlamsız bulunmuştur $(\mathrm{P}>0.05)$. Borulu su iletim kanallarına sahip sulama şebekelerinde sulama performansı yüksek olması beklenirken, kaplamalı ve kanalet su iletim kanallarına sahip olan sulama şebekeleri daha yüksek performans göstermiştir. Sonuçta sulama şebeke performans göstergeleri kanal çeşitleri ve uzunluklarının yanında yönetim, işletim gibi birçok etkene bağlı olduğu belirlenmiştir.

\section{Araştırma Makalesi}

Makale Tarihçesi

Geliş Tarihi : :26.12.2018

Kabul Tarihi : 10.03 .2019

\section{Anahtar Kelimeler}

Sulama kanal çeşitleri,

Sulama kanal uzunlukları,

Sulama performans göstergeleri,

Sulama şebekeleri

\section{The Effect of Irrigation Channel Type and Length on Irrigation Performance Indicators}

\section{ABSTRACT}

Channel types are of great importance in the effective use of water in irrigation schemes. In this study, the effects of main channel systems type and lengths on the water distribution performance indicators for 9 irrigation schemes in the 2nd District of the General Directorate of State Hydraulic Works were investigated. Correlation was used to determine the relationship between channel lengths and water distribution performance indicators. Cluster analysis was used to divide irrigation schemes into homogeneous groups according to channel types. Biplot charts which are formed as a result of principle component analysis were used to interpret all indicators together. As a result, there was a correlation between channel lengths and irrigation ratio as well as annual irrigation water supplied to users per unit command area $(\mathrm{P}<0.01)$. The interaction between channel types and lengths and other water distribution performance indicators was not statistically significant $(\mathrm{P}>0.05)$. While the water distribution performance of irrigation schemes with piped water delivery systems was expected to be high, irrigation schemes with classic and canalette channels showed higher performance. As a result, performance indicators were determined to be dependent on many factors such as management and operation besides channel types and lengths in irrigation schemes.

\section{Research Article}

$\begin{array}{ll}\text { Article History } & \\ \text { Received } & : 26.12 .2018 \\ \text { Accepted } & : 10.03 .2019\end{array}$

Keywords

Irrigation channel types

Irrigation channel length

Irrigation performance indicators

Irrigation schemes 


\section{GİRIŞ}

Dünya nüfusu hızla artarken yaşam için gerekli olan kaynaklar ise değişen iklim koşulları ve insan etkileri nedeniyle her geçen gün azalmaktadır. Günümüzde her açıdan verimlilik ön plana çıkmaktadır. Eldeki kıt imkanlardan maksimum yarar sağlamak için her alanda çalışmalar yapılmaktadır. Tarımda birim alanda üretimin artırılması maksimum verim alınarak gerekli ihtiyacın karşılanması yapılan çalışmaların başlıca hedeflerindendir. Tarımsal faaliyetlerde en önemli unsur sudur. Kullanılabilir suyun kıtlığı ve her geçen gün azalması, suyun verimli kullanılmasının önemini ortaya koymaktadır.

Sulama şebekelerinin su ihtiyacını karşılamak birçok Akdeniz ülkesinde olduğu gibi Türkiye'de de önemli bir sorun olarak ortaya çıkmaktadır. Sulama şebekelerinin izleme ve değerlendirilmesi bu sorunların çözümlenmesinde önem taşımaktadır. Araştırmacılar sulama şebekelerini değerlendirmek için birtakım performans göstergeleri geliştirmişlerdir (Molden ve ark. 1998). Bu göstergeler sulama şebekelerinin modernizasyonunda (Renault ve ark. 2007) ve sonraki çalışmalarda genişletilerek kullanılmıştır (Burt, 2001; Malano ve ark. 2004). Bu göstergeler sulama şebekelerinin performansı hakkında genel bilgiler vermektedir. Türkiye'de ve Dünyada sulama şebekelerinin sulama performanslarının değerlendirilmesi suyun etkin kullanımı açısından önem taşımakta ve birçok araştırmacı tarafından bu konuda çalışmalar yürütülmüştür. Değirmenci (2001) Türkiye'de farklı bölgelerde bulunan 158 adet sulama şebekesini, Çakmak ve ark. (2004) Türkiye'nin Doğu Anadolu Bölgesinde bulunan sulama şebekelerini değerlendirmek amaciyla performans göstergelerinden yararlanmıştır. Akçay ve Tunalı (2016) Büyük Menderes ve Aşağı Gediz Havzası sulama birliklerinin üretim ve su kullanım performanslarının karşılaştırmalı olarak değerlendirmiştir. Akkuzu ve Mengü (2011) Alaşehir yöresi sulama birliklerini arazi-su verimliliği ve su temini açısından değerlendirmişlerdir. RodriguezDíaz ve ark. (2008) sulama şebekelerini değerlendirmek amacıyla İspanya'nın Endülüs Bölgesinde yaptıkları çalışmada çok değişkenli istatistiksel yöntemlerden yararlanmıştır. Alcon ve ark. (2017) sulama performans göstergeleri ile sulama şebekelerinin bazı özellikleri arasındaki ilişkiyi panel regresyon ile açıklamıştır.

Türkiye'de DSİ (Devlet Su İşleri) tarafından inşa edilen ve su kullanıcı örgütlerine devredilen sulama şebekelerinde sulama kanallarının \%43'ü kaplamalı, \%35’i kanalet ve \%17'si borulu su iletim ve dağıtım kanallarından oluşmaktadır. Bu sulama şebekelerinin hizmet verdiği alanlarda çiftçilerin yaklaşık \%91'i yüzeysel, \%8'i yağmurlama ve \%1'i damla sulama yöntemlerini kullanmaktadır. Ayrıca bu sulama şebekelerinin ortalama sulama oranı \%62'dir. Sulanan alanlarda en yüksek ekiliş oranına sahip bitkiler mısır (\%26), pamuk (\%13) ve hububat'tır (DSI, 2017). Türkiye'de sulama oranının düşük olması ve sulama suyu ihtiyacının karşılanamamasının nedenlerinden biri de su iletim kanalları çeşit ve teknolojisidir.

$\mathrm{Bu}$ çalışmanın amacı Ege Bölgesinde bulanan 9 sulama şebekesinin sulama ana kanal çeşitlerinin ve uzunluklarının su dağıtım performans göstergeleri (sulama oranı, birim sulama/sulanan alana dağıtılan toplam sulama suyu miktarı ve su temin oranı) üzerine etkisini araştırmaktır.

\section{MATERYAL ve METOT}

\section{Materyal}

Çalışmada materyal olarak Ege Bölgesinde bulunan Menemen, Salihli, Ahmetli, Sarıgöl, Alaşehir, Bergama, Seferihisar, Kınık ve Küçükler sulama şebekeleri seçilmiştir. $\mathrm{Bu}$ sulama şebekelerinde sulama ana kanal çeşitlerinin kullanım yüzdeleri Şekil 1 'de verilmiştir.

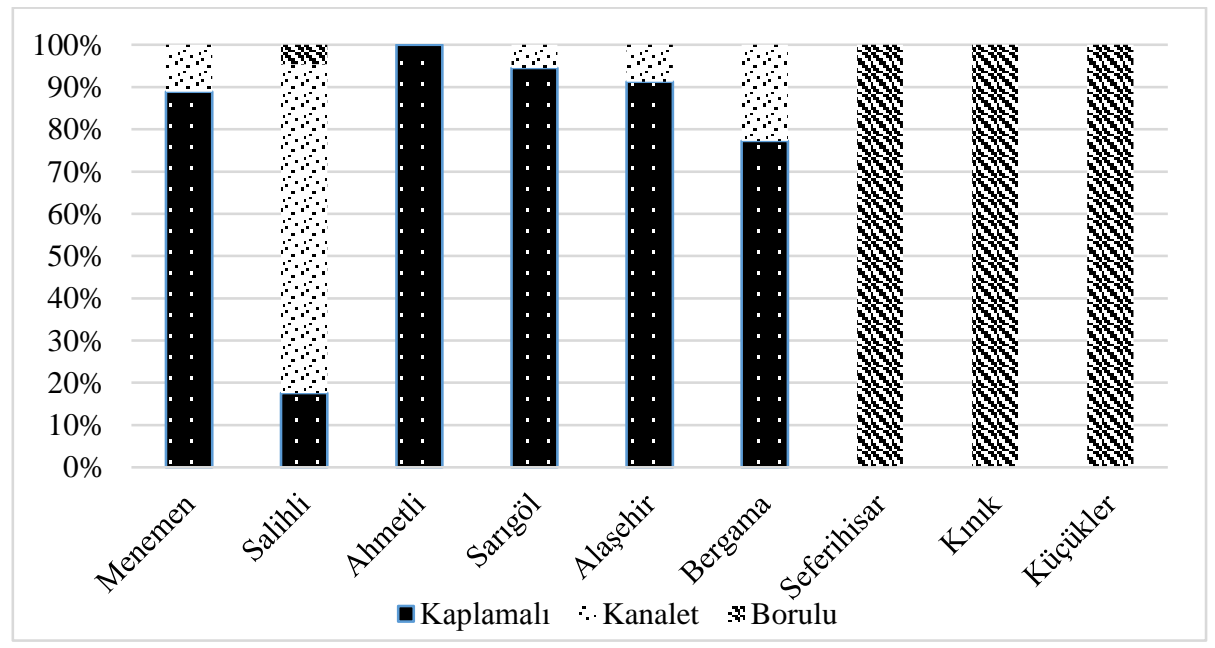

Şekil 1. Sulama şebekelerinde kullanılan su iletim kanal çeşitleri 
Çalışma yapılan bölgede sulama şebekelerinin kaplamalı, kanalet ve borulu sulama ana kanal uzunluğu sirasıyla 1337.3 , 2918.8 ve $351.6 \mathrm{~km}$ 'dir. Seferihisar, Kınık ve Küçükler sulama şebekelerinde sadece borulu su iletim kanalları kullanılırken, Ahmetli sulama şebekesinde sadece kaplamalı su iletim kanalları kullanılmaktadır. Salihli sulama şebekesi ise yaklaşık \%70'i kanalet su iletim sistemine sahiptir. Araştırma alanı olarak Ege Bölgesinin seçilmesinde tüm kanalları temsil eden sulama şebekelerinin bulunması etkili olmuştur. Bölgede toplam 12 adet büyük ölçekli sulama şebekesi (toplam sulama alanı 1000 ha'dan büyük) bulunmakta ve 140182 ha'llk bir alana hizmet etmektedir. Materyal olarak seçilen sulama şebekelerinin seçiminde verilerin ulaşılabilir olması etkili olmuştur. Çizelge 1'de genel özellikleri verilen sulama şebekelerinin toplam sulama alanı bölgedeki toplam sulama alanının \%81.66'sını temsil etmektedir. Calışmada kullanılan veriler ise DSİ Genel Müdürlüğü izleme ve değerlendirme raporlarından temin edilmiștir (DSI, 2017).

\section{Metot}

Sulama şebekelerinin değerlendirilmesinde sulama oranı (Değirmenci, 2001), birim sulanan/sulama alanına dağıtılan toplam sulama suyu miktarı ve su temin oranı (Malano ve Burton, 2001) performans göstergeleri kullanılmıştır. $\mathrm{Bu}$ göstergelerin hesaplanmasında ihtiyaç duyulan veriler Çizelge 2'de verilmiştir. Sulama oranı, sulama şebekesinde toplam sulanan I. ürün alanını, şebekeye alınan toplam sulama suyu miktarı $\left(\mathrm{m}^{3}\right)$, su kaynağından şebekeye saptırılan su miktarını ve toplam sulama suyu ihtiyacı $\left(\mathrm{m}^{3}\right)$, bitki su tüketimi ve sulama randımanı dikkate alınarak DSI tarafindan hesaplanmış olan parametrelerdir. Birim alana (da) düşen ana sulama kanal uzunluğunu (m) hesaplamak amaciyla ise aşağıda verilen formüllerden yararlanılmıştır (Eşitlik $1,2,3)$.

Çizelge 1. Sulama şebekeleri genel özellikleri

\begin{tabular}{|c|c|c|c|c|c|c|c|}
\hline Sulama & Sulamaalanı & Cazibe & Pompaj & İşletmeye & \multicolumn{3}{|c|}{ Başlıca ürünler } \\
\hline Menemen & 22865 & $\mathrm{x}$ & $\mathrm{x}$ & 1944 & $\begin{array}{l}\text { Pamuk } \\
(\% 65)\end{array}$ & $\begin{array}{l}\text { Misir } \\
(\% 11)\end{array}$ & $\begin{array}{l}\mathrm{Bag} \\
(\% 5)\end{array}$ \\
\hline Salihli & 22797 & $\mathrm{x}$ & $\mathrm{x}$ & 1944 & $\begin{array}{l}\text { Bağ } \\
(\% 54)\end{array}$ & $\begin{array}{l}\text { Misir } \\
(\% 29)\end{array}$ & $\begin{array}{l}\text { Pamuk } \\
(\% 6)\end{array}$ \\
\hline Ahmetli & 50232 & $\mathrm{x}$ & & 1954 & $\begin{array}{l}\mathrm{Bağ} \\
(\% 49)\end{array}$ & $\begin{array}{l}\text { Misir } \\
(\% 38)\end{array}$ & $\begin{array}{l}\text { Pamuk } \\
(\% 4)\end{array}$ \\
\hline Sarıgöl & 1927 & $\mathrm{x}$ & & 1969 & $\begin{array}{l}\text { Bağ } \\
(\% 97)\end{array}$ & $\begin{array}{l}\text { Fidan } \\
(\% 3)\end{array}$ & - \\
\hline Alaşehir & 11806 & $\mathrm{x}$ & $\mathrm{x}$ & 1979 & $\begin{array}{l}\mathrm{Bağ} \\
(\% 99)\end{array}$ & $\begin{array}{l}\text { Fidan } \\
(\% 1)\end{array}$ & - \\
\hline Bergama & 3716 & $\mathrm{x}$ & & 1989 & $\begin{array}{l}\text { Misir } \\
(\% 48)\end{array}$ & Pamuk (\%16) & Ayçiçeği (\%14) \\
\hline Seferihisar & 1129 & $\mathrm{x}$ & & 1997 & $\begin{array}{l}\text { Narenciy } \\
\text { e (\%89) }\end{array}$ & $\begin{array}{l}\text { Sebze } \\
(\% 6)\end{array}$ & $\begin{array}{c}\text { Misir } \\
(\% 5)\end{array}$ \\
\hline
\end{tabular}

Çizelge 2. Seçilen performans göstergeleri ve ihtiyaç duyulan veriler

\begin{tabular}{|c|c|c|}
\hline Gösterge kodu & Gösterge adı & İhtiyaç duyulan veriler \\
\hline Soranı & Sulama oranı (\%) & $\begin{array}{l}\text { Sulanan alan (ha) } \\
\text { Sulama alanı (ha) }\end{array}$ \\
\hline Bsulanan & $\begin{array}{l}\text { Birim sulanan alana } \\
\text { dağıtılan sulama suyu } \\
\text { miktarı }\left(\mathrm{m}^{3} \mathrm{ha}^{-1}\right)\end{array}$ & $\begin{array}{l}\text { Şebekeye alınan toplam sulama suyu miktarı }\left(\mathrm{m}^{3}\right) \\
\text { Sulanan alan (ha) }\end{array}$ \\
\hline Bsulama & $\begin{array}{l}\text { Birim sulama alanına } \\
\text { dağıtılan sulama suyu } \\
\text { miktarı }\left(\mathrm{m}^{3} \mathrm{ha}^{-1}\right)\end{array}$ & $\begin{array}{l}\text { Şebekeye alınan toplam sulama suyu miktarı }\left(\mathrm{m}^{3}\right) \\
\text { Sulama alanı (ha) }\end{array}$ \\
\hline Stemino & Su temin oranı & $\begin{array}{l}\text { Şebekeye alınan toplam sulama suyu miktarı }\left(\mathrm{m}^{3}\right) \\
\text { Toplam sulama suyu ihtiyacı }\left(\mathrm{m}^{3}\right)\end{array}$ \\
\hline
\end{tabular}

Birim sulama alanına düşen kaplamalı kanal uzunluğu $=\frac{\text { Toplam kaplamalı kanal uzunluğu (m) }}{\text { Sulama }}$

Birim sulama alanına düşen kanaletli kanal uzunluğu $=\frac{\text { Toplam kanelet kanal uzunluğu (m) }}{\text { Sulama alanı (ha) }}$

Birim sulama alanına düşen borulu kanal uzunluğu $=\frac{\text { Toplam borulu kanal uzunluğu (m) }}{\text { Sulama alanı (ha) }}$ 


\section{İstatiksel Değerlendirme}

Yapılan çalışmada sulama performans göstergeleri ile birim sulama alanına düssen kaplamalı, kanalet ve borulu kanal uzunlukları arasındaki ilişkiyi belirlemek amacıyla korelasyon yapılmıştır. Sulama şebekelerini her bir kanal çeşidinde birim alana düşen kanal uzunluklarına göre kümeleme analizi yapılmıştır. $\mathrm{Bu}$ analiz ile kanal çeşitleri ve uzunluklarının performans göstergelerine olan etkisinin homojen gruplarda incelenmesi amaçlanmıştır. Sulama şebekeleri, sulama performans göstergeleri ve birim alana düşen kanal uzunlukları arasındaki ilişkiyi bir arada incelemek amacıyla biplot grafiğinden yararlanılmıştır. Biplot grafikleri temel bileşenler analizi sonucunda oluşturulmuştur.

\section{BULGULAR ve TARTIŞMA}

Bölgede bulunan sulama şebekelerine ait sulama performans göstergeleri ve birim sulama alanına düşen kaplamalı, kanalet, borulu ana kanal uzunlukları ortalama ve standart sapma değerleri Çizelge 3’te verilmiştir.

Çizelge 3. Sulama performans göstergeleri ve birim alana düşen kaplamalı, kanalet, borulu sulama kanal uzunlukları ortalamaları ve standart sapma değerleri

\begin{tabular}{|c|c|c|c|c|c|c|c|}
\hline $\begin{array}{l}\text { Sulama } \\
\text { şebekesi }\end{array}$ & Soranı & $\begin{array}{l}\text { Bsulanan } \\
\left(\mathrm{m}^{3} \mathrm{ha}^{-1}\right)\end{array}$ & $\begin{array}{l}\text { Bsulama } \\
\left(\mathrm{m}^{3} \mathrm{ha}^{-1}\right)\end{array}$ & Stemino & $\begin{array}{l}\text { Kaplamalı } \\
\left(\mathrm{m} \mathrm{da}^{-1}\right)\end{array}$ & $\begin{array}{l}\text { Kanalet } \\
\left(\mathrm{m} \mathrm{da}^{-1}\right)\end{array}$ & $\begin{array}{l}\text { Borulu } \\
\left(\mathrm{m} \mathrm{da}^{-1}\right)\end{array}$ \\
\hline Menemen & $\begin{array}{l}75.10 \\
(4.64)^{*}\end{array}$ & $\begin{array}{l}8426.10 \\
(1017.27)\end{array}$ & $\begin{array}{l}6324.90 \\
(801.73)\end{array}$ & $\begin{array}{l}1.60 \\
(0.40)\end{array}$ & $\begin{array}{l}30.22 \\
(0)\end{array}$ & $\begin{array}{l}3.76 \\
(0)\end{array}$ & - \\
\hline Salihli & $\begin{array}{l}52.58 \\
(4.23)\end{array}$ & $\begin{array}{l}11029.40 \\
(1378.66)\end{array}$ & $\begin{array}{l}5767.79 \\
(521.55)\end{array}$ & $\begin{array}{l}2.13 \\
(0.63)\end{array}$ & $\begin{array}{l}8.42 \\
(0.24)\end{array}$ & $\begin{array}{l}37.42 \\
(1.07)\end{array}$ & $\begin{array}{l}2.19 \\
(0.06)\end{array}$ \\
\hline Ahmetli & $\begin{array}{l}41.05 \\
(2.82)\end{array}$ & $\begin{array}{l}9471.13 \\
(773.95)\end{array}$ & $\begin{array}{l}3896.37 \\
(505.67)\end{array}$ & $\begin{array}{l}2.07 \\
(0.58)\end{array}$ & $\begin{array}{l}37.15 \\
(0.42)\end{array}$ & - & - \\
\hline Sarıgöl & $\begin{array}{l}28.29 \\
(6.86)\end{array}$ & $\begin{array}{l}12709.11 \\
(4924.00)\end{array}$ & $\begin{array}{l}3505.45 \\
(1538.84)\end{array}$ & $\begin{array}{l}2.80 \\
(1.04)\end{array}$ & $\begin{array}{l}106.38 \\
\text { (0) }\end{array}$ & $\begin{array}{l}6.23 \\
(0)\end{array}$ & - \\
\hline Alaşehir & $\begin{array}{l}39.86 \\
(4.94)\end{array}$ & $\begin{array}{l}8314.21 \\
(1233.41)\end{array}$ & $\begin{array}{l}3281.49 \\
(395.12)\end{array}$ & $\begin{array}{l}1.44 \\
(0.43)\end{array}$ & $\begin{array}{l}44.07 \\
(0)\end{array}$ & $\begin{array}{l}4.24 \\
(0)\end{array}$ & \\
\hline Bergama & $\begin{array}{l}46.52 \\
(3.67)\end{array}$ & $\begin{array}{l}8168.48 \\
(1439.93)\end{array}$ & $\begin{array}{l}3796.76 \\
(693.81)\end{array}$ & $\begin{array}{l}1.24 \\
(0.34)\end{array}$ & $\begin{array}{l}53.82 \\
(0)\end{array}$ & $\begin{array}{l}15.88 \\
(0)\end{array}$ & \\
\hline Seferihisar & $\begin{array}{l}49.37 \\
(1.21)\end{array}$ & $\begin{array}{l}8266.82 \\
(2761.47)\end{array}$ & $\begin{array}{l}4087.87 \\
(1369.10)\end{array}$ & $\begin{array}{l}1.25 \\
(0.56)\end{array}$ & - & - & $\begin{array}{l}88.33 \\
(2.57)\end{array}$ \\
\hline Kınık & $\begin{array}{l}19.46 \\
(20.14)\end{array}$ & $\begin{array}{l}12426.40 \\
(9675.99)\end{array}$ & $\begin{array}{l}2029.00 \\
(1786.20)\end{array}$ & $\begin{array}{l}2.29 \\
(2.05)\end{array}$ & - & - & $\begin{array}{l}33.62 \\
(0)\end{array}$ \\
\hline Küçükler & $\begin{array}{l}20.97 \\
(10.86)\end{array}$ & $\begin{array}{l}10916.53 \\
(5852.89)\end{array}$ & $\begin{array}{l}1968.81 \\
(733.30)\end{array}$ & $\begin{array}{l}1.71 \\
(1.12)\end{array}$ & & - & $\begin{array}{l}33.22 \\
(0)\end{array}$ \\
\hline
\end{tabular}

${ }^{\bar{*}}$ Standart sapma, Soranı: sulama oranı, Bsulanan: birim sulanan alana dağıtılan toplam sulama suyu miktarı, Bsulama: birim sulama alanına dağıtılan sulama suyu miktarı, Stemino: su temin oranı, Kaplamalı: birim sulama alanına düşen kaplamalı kanal uzunluğu, Kanalet: birim sulama alanına düşen kanalet uzunluğu, Borulu: birim sulama alanına düşen borulu kanal uzunluğu

Araştırma sonuçlarına göre en düşük ortalama sulama oranına sahip olan sulama şebekesi \%19.46 ile Kınık'tır. Ayrıca bu sulama şebekesinin standart sapması 20.14'tür. Bu durum Kınık sulama şebekesi sulama oranının yıllar içinde çok değişkenlik gösterdiğini kanıtlamaktadır. En yüksek ortalama sulama oranı \%75.10 ile Menemen sulama şebekesinde hesaplanmıştır. DSİ (2017)'ye göre Türkiye ortalama sulama oranı \%62'dir. Ortalama sulama oranı Menemen sulama şebekesi hariç tüm sulama şebekelerinde Türkiye ortalamasının altındadır. Bölgede sulama oranının düşük olmasının sebepleri yağışların yeterli görülmesi ve su talebinin olmaması (\%30), nadas (\%10), sosyal ve ekonomik nedenler (\%6)'dir.

Birim sulanan alana dağıtılan toplam sulama suyu ortalaması en yüksek $12709.11 \mathrm{~m}^{3} \mathrm{ha}^{-1}$ ile Sarıöl sulama şebekesinde, en düşük ise $8168.48 \mathrm{~m}^{3} \mathrm{ha}^{-1}$ ile Bergama sulama şebekesinde hesaplanmıştır. Eliçabuk ve Toprak (2017) kaplamalı ve kanalet su iletim sistemine sahip Gevrekli sulama şebekesinde 2008-2013 yılları verilerine göre yaptığı çalışmaya Bsulanan değerini 2577-5273 $\mathrm{m}^{3} \mathrm{ha}^{-1}$ arasında saptamışlardır. Ege Bölgesinde bulunan sulama şebekeleri Eliçabuk ve Toprak (2017)'ye göre düşük performans göstermektedir. Birim sulama alanına dağıtılan toplam sulama suyu miktarı en yüksek $6324.90 \mathrm{~m}^{3} \mathrm{ha}^{-1}$ ile Menemen sulama şebekesinde, en düşük ise $1968.81 \mathrm{~m}^{3} \mathrm{ha}^{-1}$ ile Küçükler sulama şebekesinde ölçülmüştür. Bsulama değeri, Cihan ve Acar (2016) Konya ili Çumra ilçesinde 2012-2014 yılları verileri ile yaptığı çalışmaya $\left(10360 \mathrm{~m}^{3} \mathrm{ha}^{-1}\right)$ göre benzerlik göstermekte, Kalender ve Toprak (2017)'de Ilgin ovasında 2007-2015 yılları verilerine göre basınçlı sulama yapan sulama şebekesine göre 
(1727 - $\left.6334 \mathrm{~m}^{3} \mathrm{ha}^{-1}\right)$ ise yüksek olduğu söylenebilir.

Su temin oranı ortalaması en düşük 1.24 ile Bergama sulama şebekesinde en yüksek ise Sarıgöl sulama şebekesinde hesaplanmıştır. Bölgede su temin oranın 1 'den yüksek olması sulama suyu ihtiyacından fazla su tüketildiğinin kanıtıdır. Arslan ve Değirmenci (2018) kaplamalı su iletim kanal sistemi kullanan Kartalkaya Sol Sahil sulama şebekesinde su temin oranını 2.68 olarak hesaplamışlardır. Su temin oranının 1'e eşit olması sulama sistemine yeterli miktarda saptırıldığını, 1'den az olması yetersiz su dağıtımının yapıldığını, 1'den fazla olması ise sulama şebekesinde fazla su dağıtımı yapıldığını göstermektedir (Molden ve ark., 1998). Buna göre araştırma alanında su temin oranı tüm sulama şebekelerinde 1'den büyüktür ve sulama suyunu ihtiyaçtan fazla kullandığını söyleyebiliriz.

Birim alana düşen kaplamalı, kanalet ve borulu su iletim kanal uzunlukları ortalamasına göre yapılan kümeleme ağaç grafiği Şekil 2'de verilmiştir. Kümeleme ağaç grafiğinde mesafe (uzaklık) yaklaşık 36 seçilerek 5 grup oluşturulmuştur.

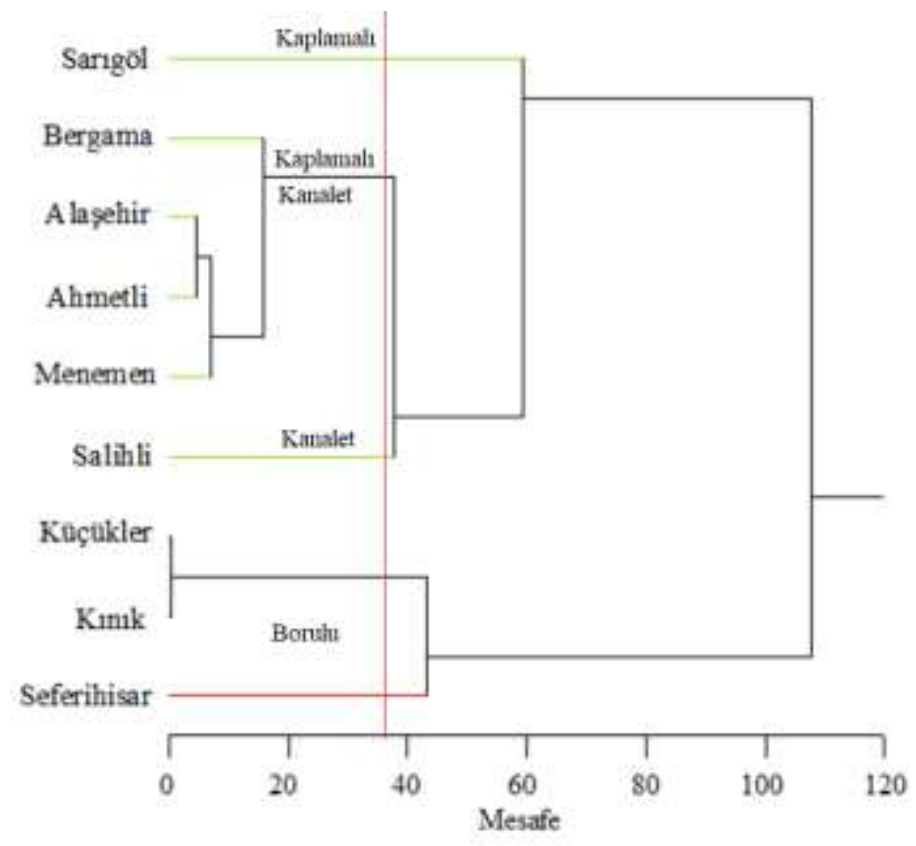

Kümeleme ağaç grafiğine göre ilk grupta yer alan Sarıgöl sulama şebekesi kaplamalı su iletim kanallarını temsil etmektedir. İkinci grupta yer alan Bergama, Alaşehir, Ahmetli, Menemen sulama şebekeleri kaplamalı ve kanaletli su iletim kanallarını temsil etmektedir. Salihli sulama şebekesi kanaletli su iletim kanalları 3. grupta yer almışlardır. Borulu su iletim kanallarını temsil eden Küçükler ve Kınık sulama şebekeleri 4. grubu, Seferihisar ise 5. grubu oluşturmuştur. Seferihisar sulama şebekesinin birim alana düşen borulu su iletim kanal uzunluğu $88.33 \mathrm{~m}$ $\mathrm{da}^{-1}$, Küçükler ve Kınık sulama şebekelerinin ise bu göstergesi yaklaşık $33 \mathrm{~m}$ da ${ }^{-1}$ 'dır. $\mathrm{Bu}$ sulama şebekelerinin su iletim kanalları \%100 borulu olduğundan aynı grupta değerlendirilmiştir. Sonuçta Küçükler, Kınık ve Seferihisar sulama şebekeleri tek grupta değerlendirilmiştir (Çizelge 4).

Oluşan gruplar incelendiğinde kaplamalı su iletim kanallarma sahip olan sulama şebekelerinin daha yüksek Soranı ve daha düşük Bsulanan, Bsulama ve Stemino göstergelerine sahip olduğu görülmektedir. $\mathrm{Bu}$ durumda 1. grup daha iyi performans göstermektedir. Borulu sulama şebekelerinin temsil edildiği 4. grup ise en düşük Soranı'na ve en düşük Bsulama değerine sahiptir.

En yüksek Stemino ise 3. grupta gerçekleşmiştir. 4. grupta su iletim kanallarinin borulu olmasina beklenen performansı göstermemektedir. Tarla düzeyinde yüzeysel sulama yöntemlerinin kullanılması （Kınık \%100, Küçükler \%20） veya yönetim, işletim sorunların bulunması 4. grubun Bsulanan değerinin 1. ve 2. gruptan yüksek olmasını açıklayabilir. Bu durum işletme, bakım ve yönetim sorunlarından kaynaklanabilir.

Performans göstergeleri ve birim alana düşen kanal uzunlukları (kaplamalı, kanalet ve borulu) arasinda yapılan korelasyon Çizelge 5’te verilmiştir. Birim alana düşen kanalet uzunluğu ve Soranı arasında (Pearson korelasyon katsayısı: 0.280; $\mathrm{P}<0.01$ ) ve Bsulama arasinda (Pearson korelasyon katsayısı: 0.428; $\mathrm{P}<0.01$ ) pozitif korelasyon bulunmuştur.Buna göre birim alana düşen kanalet uzunluğu arttıkça Soranı ve Bsulama artmaktadır.

Şekil 2. Kümeleme ağaç grafiği

Çizelge 4. Kanal çeşitlerini temsil eden sulama şebekeleri ve ortalama performans gösterge değerleri

\begin{tabular}{|c|c|c|c|c|c|c|}
\hline Grup & Soranı & $\begin{array}{l}\text { Bsulanan } \\
\left(\mathrm{m}^{3} \mathrm{ha}^{-1}\right)\end{array}$ & $\begin{array}{l}\text { Bsulama } \\
\left(\mathrm{m}^{3} \mathrm{ha}^{-1}\right)\end{array}$ & Stemino & Sulama şebekeleri & $\begin{array}{l}\text { Temsil edilen } \\
\text { kanal çeşidi }\end{array}$ \\
\hline 1. Grup & 75.10 & 8426.10 & 6324.90 & 1.60 & Sarıgöl & Kaplamalı \\
\hline 2. Grup & 50.63 & 8594.98 & 4324.88 & 1.59 & $\begin{array}{l}\text { Bergama, Alaşehir, } \\
\text { Ahmetli, Menemen }\end{array}$ & $\begin{array}{l}\text { Kaplamalı } \\
\text { Kanalet }\end{array}$ \\
\hline 3. Grup & 52.58 & 11029.40 & 5767.79 & 2.13 & Salihli & Kanalet \\
\hline 4. Grup & 29.93 & 10536.58 & 2695.23 & 1.75 & $\begin{array}{l}\text { Küçükler, } \\
\text { Seferihisar }\end{array}$ & Borulu \\
\hline
\end{tabular}

Soranı: sulama oranı, Bsulanan: birim sulanan alana dağıtılan toplam sulama suyu miktarı, Bsulama: birim sulama alanına dağıtılan sulama suyu miktarı, Stemino: su temin oranı 
Çizelge 5. Performans göstergeleri ve birim alana düşen kanal uzunlukları arasındaki korelasyon katsayıları

\begin{tabular}{lccccccc} 
& Soranı & Bsulanan & Bsulama & Stemino & Kaplamalı & Kanalet & Borulu \\
Soranı & 1 & $-0.354^{* *}$ & $0.763^{* *}$ & $-0.296^{*}$ & -0.019 & $\mathbf{0 . 2 8 0 ^ { * }}$ & -0.144 \\
Bsulanan & & 1 & $0.248^{*}$ & $0.870^{* *}$ & 0.050 & 0.033 & -0.032 \\
Bsulama & & & 1 & 0.220 & 0.056 & $\mathbf{0 . 4 2 8 ^ { * * }}$ & -0.224 \\
Stemino & & & & 1 & 0.189 & 0.042 & -0.157 \\
Kaplamalı & & & & & 1 & 0.007 & $-0.575^{* *}$ \\
Kanalet & & & & & & 1 & $-0.365^{* *}$ \\
Borulu & & & & & & & 1 \\
\hline
\end{tabular}

Önem derecesi ${ }^{*} \mathrm{p}<0.10,{ }^{* *} \mathrm{p}<0.05,{ }^{* * *} \mathrm{p}<0.01$, Soranıः sulama oranı, Bsulanan: birim sulanan alana dağıtılan toplam sulama suyu miktarı, Bsulama: birim sulama alanına dağıtılan sulama suyu miktarı, Stemino: su temin oranı

Birim alana düşen kaplamalı ve borulu su iletim kanal uzunlukları ise su dağıtım performans göstergelerini istatistiksel olarak önemli derecede etkilemektedir $(\mathrm{P}>0.05)$.

Temel bileşenler analizi sonucunda elde edilen biplot grafiği Şekil 3’te verilmiştir. Şekil 3 hesaplanan göstergeler ile sulama şebekeleri arasındaki ilişkiyi açıklamaktadır. Menemen sulama şebekesinde Soranı ve Bsulama göstergelerinde daha yüksek olduğu ayrıca birim alana düşen kanalet uzunluğunun daha yüksek olduğu gözlemlenmektedir. Stemino, Bsulanan ve birim alana düşen kaplamalı su iletim kanal uzunluğu arasında pozitif korelasyon bulunurken, bu göstergeler birim alana düşen borulu kanal uzunluğu ile negatif korelasyona sahiptir. Çizelge 5 incelendiğinde göstergeler arasındaki korelasyon Şekil 3 'te verilen biplot grafiğini desteklemektedir. Göstergeleri temsil eden mavi çizgiler arasındaki açı küçüldükçe pozitif korelasyonu gösterirken, birbirine zit yönde olan mavi çizgiler negatif korelasyonu göstermektedir. Ancak bu korelasyonun istatistiksel olarak anlamlı olup olmadığ anlaşılmaktadır. Aslında temel bileşenler analizi sonucunda oluşan biplot grafiği sulama şebekeleri ve tüm göstergelerin bir arada yorumlanması ve tek bir grafik içinde yorumlanmasına yardımcı olmaktadır. Ayrıca göstergeleri temsil eden mavi çizgilerin ucuna yakın sulama şebekeleri diğer sulama şebekelerine göre daha yüksek değer aldığını ifade etmektedir.

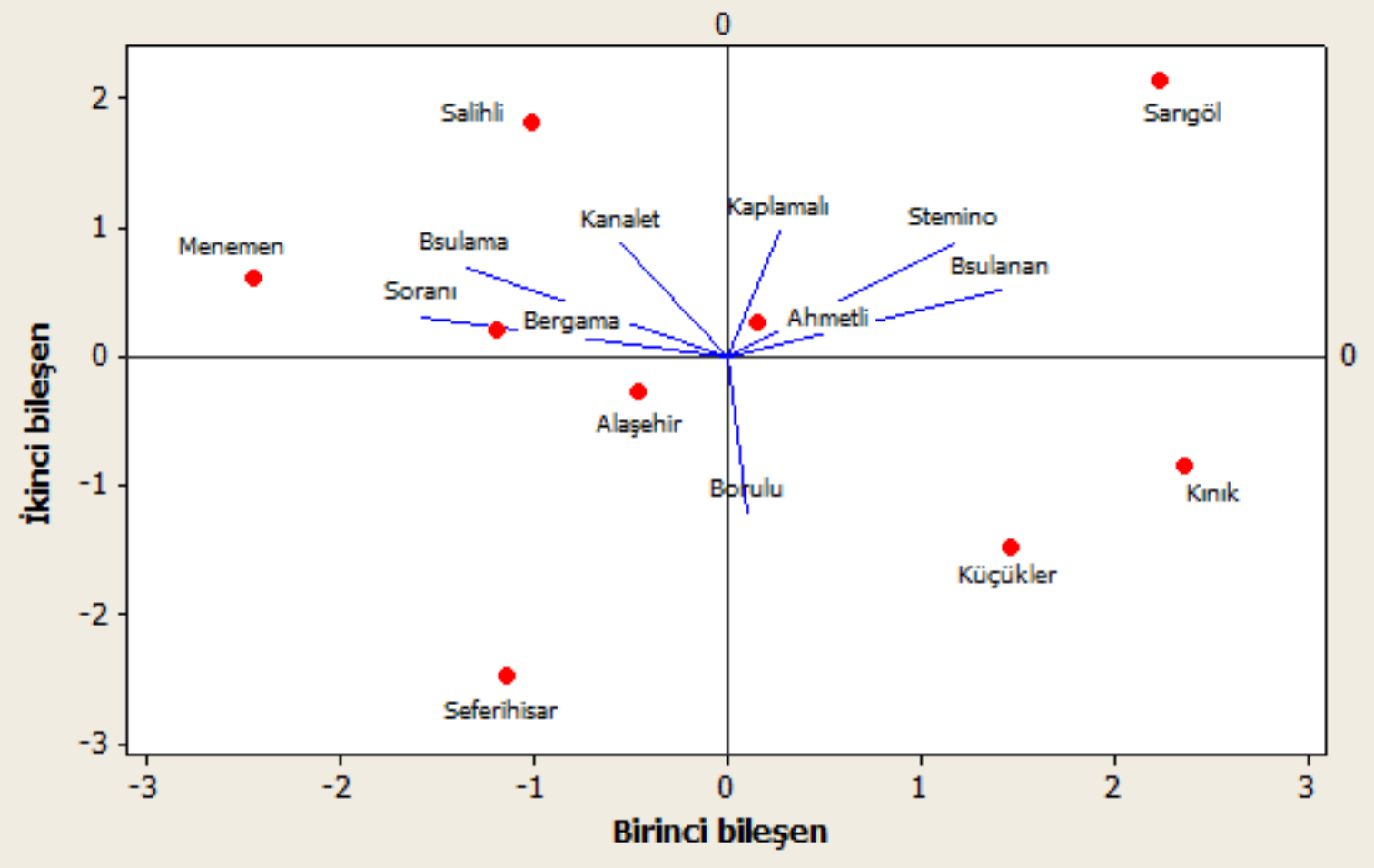

Şekil 3. Biplot grafiği 


\section{SONUÇ}

Ana sulama kanal çeşitleri ve uzunluklarının sulama performans göstergeleri üzerine etkisinin araştırıldığ bu çalışmada, Ege Bölgesinde bulunan Menemen, Salihli, Ahmetli, Sarıgöl, Alaşehir, Bergama, Seferihisar, Kınık ve Küçükler sulama şebekelerine ait 2009-2016 verileri kullanılarak değerlendirilmiştir. Sonuçta borulu su iletim kanallarına sahip sulama şebekelerinin birim sulama alanına dağıtılan toplam sulama suyu miktarını azalttığı gözlemlenmiştir. Ayrica bu sulama şebekelerinde sulama oranının düşük olduğu görülmüştür. Araştırma sonucuna göre sadece kanaletli su iletim kanalları sulama oranı ve birim sulanan alana dağıtılan toplam sulama suyu miktarına etki etmiştir. Ancak bu göstergelere etki eden diğer unsurlar da bulunmaktadır. Örneğin, Kınık sulama şebekesinde su iletiminin borulu sulama kanalları ile yapılmasına rağmen, çiftçiler sulanan alanda sadece yüzeysel sulama yöntemleri kullanmışlardır. Buna benzer durumlar su dağıtım performansını olumsuz yönde etkilemektedir. Sonuç olarak su iletim kanalları su tasarrufu sağlamaktadır ancak çiftçi düzeyinde teknoloji kullanımının düşük olması su dağıtım performans göstergelerine negatif etkide bulunarak performansı düşürmektedir. Borulu su iletim kanallarına sahip sulama şebekelerinin performansı, kanalet ve kaplamalı kanallara sahip olan sulama şebekelerinden düşük olması işletim ve yönetim modernizasyon ihtiyacı olduğunu göstermektedir.

\section{KAYNAKLAR}

Akçay S, Tunalı SP 2016. Aşağı Büyük Menderes ve Aşağı Gediz Havzası Sulama Birliklerinin Üretim ve Su Kullanım Performanslarının Karşılaştırmalı Olarak Değerlendirilmesi. Türkiye Tarımsal Araştırmalar Dergisi, 3(1): 64-73.

Akkuzu E, Mengü GP 2011. Alaşehir yöresi sulama birliklerinin arazi-su verimliliği ve su temini açısından değerlendirilmesi. Ege Üniversitesi Ziraat Fakültesi Dergisi, 48(2): 119-126.

Alcon F, García-Bastida PA, Soto-García M, MartínezAlvarez V, Martin-Gorriz B, Baille A 2017. Explaining the performance of irrigation communities in a water-scarce region. Irrigation Science, 35(3): 193-203.

Arslan F, Değirmenci H 2018. Sulama Şebekelerinin İşletme-Bakım ve Yönetim Modernizasyonunda RAP-MASSCOTE Yaklaşımı: Kahramanmaraş Sol Sahil Sulama Şebekesi Örneği, Atatürk Üniversitesi Ziraat Fakültesi Dergisi, 49(1): 45-51.
Burt C 2001. Rapid Appraisal Process (RAP) and Benchmarking: Explanation and Tools. Water Control. 2001. http://www.watercontrol.org/ tools/rap-eng-2002, URL: 18 August 2018.

Cihan I, Acar B 2016. Performance of Ova Water User Association in Konya-Turkey, World Journal of Innovative Research, 1(2): 25-28.

Çakmak B, Beyribey M, Yildirim YE, Kodal S 2004. Benchmarking performance of irrigation schemes: a case study from Turkey. Irrigation and Drainage: The journal of the International Commission on Irrigation and Drainage, 53(2): 155-163.

Değirmenci H 2001. Devredilen sulama şebekelerinin karşılaştırma göstergeleri ile değerlendirilmesi. Uludağ Üniversitesi Ziraat Fakültesi Dergisi, 15:31-41.

DSI 2017. 2016 Yılı DSİ'ce İşletilen ve Devredilen Sulama Tesisleri Değerlendirme Raporu. Devlet Su İşleri Genel Müdürlüğü, Ankara, Türkiye.

Eliçabuk C, Topak R 2017. Gevrekli sulama birliği'nde sulama performansının değerlendirilmesi. Selçuk Tarım Bilimleri Dergisi, 3(2): 191-199.

Kalender MA, Topak R 2017. Irrigation Performance of Ilgin Plain Irrigation Association. Selcuk J Agr Food Sci, 31(2): 59-67.

Malano H, Burton M 2001. International Program for Technology and Research in Irrigation and Drainage guidelines for benchmarking performance in the irrigation and drainage sector. IPTRID Secretariat, Food and Agriculture Organization of the United Nations.

Malano H, Burton M, Makin I 2004. Benchmarking performance in the irrigation and drainage sector: a tool for change. Irrigation and Drainage, 53:119133.

Molden DJ, Sakthivadivel, R, Perry CJ, Fraiture CD, Kloezen WH 1998. Indicators for Comparing Performance of Irrigated Agricultural Systems. IWMI, 1998, Research Report 20, Colombo, 26 p.

Renault D, Facon T, Wahaj R 2007. Modernizing Irrigation Management: The MASSCOTE Approach-Mapping System and Services for Canal Operation Techniques (Vol 62). Food \& Agriculture Org..

Rodríguez-Díaz JA, Camacho-Poyato E, Lopez-Luque R, Pérez-Urrestarazu L 2008. Benchmarking and multivariate data analysis techniques for improving the efficiency of irrigation districts: an application in Spain. Agricultural systems, 96(1-3): 250-259. 